\title{
Population Subdivision of Fusarium graminearum from Barley and Wheat in the Upper Midwestern United States at the Turn of the Century
}

\author{
Junmin Liang, Lotus Lofgren, Zhanhong Ma, Todd J. Ward, and H. Corby Kistler
}

First and third authors: Department of Plant Pathology, China Agricultural University, Beijing, China, 100193; first, second, and fifth authors: Department of Plant Pathology, University of Minnesota, St. Paul 55108; fourth author: U.S. Department of Agriculture, Agricultural Research Service (USDA-ARS), Peoria IL 61604; and fifth author: USDA-ARS, Cereal Disease Laboratory, University of Minnesota, St. Paul 55108.

Accepted for publication 19 June 2015.

\begin{abstract}
Liang, J., Lofgren, L., Ma, Z., Ward, T. J., and Kistler, H. C. 2015. Population subdivision of Fusarium graminearum from barley and wheat in the upper Midwestern United States at the turn of the century. Phytopathology 105: 1466-1474.

Fusarium graminearum, the causal agent of Fusarium head blight (FHB) in wheat and barley, is one of the most economically destructive pathogens of these grains worldwide. Recent population genetic studies of the pathogen obtained from wheat in North America supported population subdivision in part correlated with the spectrum of trichothecene mycotoxins (chemotype) produced by individuals within each population. In contrast, a recent study of $F$. graminearum obtained from diseased barley in the upper Midwestern United States concluded that only a single population was present, consisting of individuals with various chemotypes. To test whether strains derived from different hosts potentially have different population dynamics, we obtained the barley strains used in the previous study and compared them with wheat strains isolated at a similar time and

geographic origin. A total of $247 F$. graminearum isolates from barley were assigned firmly into two clusters using a Bayesian clustering method. Subdivision within the barley population corresponded to the previously described NA1 (correlated with the 15ADON chemotype) and NA2 (correlated with the $3 \mathrm{ADON}$ chemotype) populations from wheat. However, in both sampling periods the barley population exhibited a higher level of genetic differentiation between NA1 and NA2 populations, fewer admixed individuals and evidence of unidirectional gene introgression (15ADON strains with NA2 genetic backgrounds). These results suggest less recombination between NA1 and NA2 populations on barley compared with wheat. The frequency of 3ADON chemotype strains in the most recently surveyed barley population suggests a latitudinal cline from the northern (49\%), central (40\%) to the southern (29\%) sampling area. The potential to produce a novel trichothecene, $3 \alpha$-acetoxy, $7 \alpha, 15$ dihydroxy-12,13-epoxytrichothe-9-ene (NX-2), was not detected in the barley population but occurred at a low rate $(2.4 \%)$ in the wheat population.
\end{abstract}

Fusarium graminearum sensu stricto (O'Donnell et al. 2004), the principal cause of Fusarium head blight (FHB) of wheat and barley, contaminates grains with several mycotoxins which pose a threat to human and animal health and create serious yield reduction and economic losses worldwide (Láday et al. 2004; McMullen et al. 1997; Qu et al. 2008; Ramirez et al. 2007; Steffenson 2003; Tóth et al. 2005; Zhang et al. 2010). North Dakota and Minnesota are among the most important barley and wheat production regions in the United States. Between 1993 and 1998, FHB epidemics led to barley yield decreases of $38 \%$ in North Dakota and $21 \%$ in Minnesota. Wheat yields dropped in these two states by 48 and $39 \%$, respectively (Anonymous 2015).

In worldwide surveys conducted to date, $F$. graminearum is widely distributed and has been reported in Asia, Africa, America, Europe, and Oceania (O'Donnell et al. 2000) and is the predominant species associated with FHB in the United States. Usually, F. graminearum produces in planta type B trichothecenes having a 7-hydroxy, 8-keto-trichothecene core structure. Based on this core structure and the acetylation position, four common trichothecenes have been identified: deoxynivalenol (DON), 3-acetyl, deoxynivalenol

Corresponding author: H. C. Kistler; E-mail address: hckist@umn.edu

*The $\boldsymbol{e}$-Xtra logo stands for "electronic extra" and indicates that two supplementary tables are published online.

http://dx.doi.org/10.1094/PHYTO-01-15-0021-R

This article is in the public domain and not copyrightable. It may be freely reprinted with customary crediting of the source. The American Phytopathological Society, 2015 .
(3ADON), 15-acetyl, deoxynivalenol (15ADON), and nivalenol (NIV). Additionally, a novel trichothecene ( $3 \alpha$-acetoxy, $7 \alpha, 15$-dihydroxy-12,13epoxytrichothe-9-ene, called NX-2) recently was identified from F. graminearum in the United States (Liang et al. 2014; Varga et al. 2015). NX-2 lacks the keto group at C-8 and thus is considered a type A trichothecene but otherwise resembles $3 \mathrm{ADON}$. Individual isolates of $F$. graminearum generally produce a limited spectrum of trichothecenes (known as chemotype) which is under genetic control at several trichothecene biosynthetic loci (Seong et al. 2009).

Previous studies indicated that the $15 \mathrm{ADON}$ chemotype was predominant in the North American $F$. graminearum population (Abramson et al. 2001; Gale et al. 2007). However, a temporal shift toward the 3ADON chemotype occurred in western Canada from 1997 to 2004 (Ward et al. 2008). A similar increase in the frequency of strains with a $3 \mathrm{ADON}$ chemotype was also observed in the upper Midwestern United States $F$. graminearum population from barley (Burlakoti et al. 2011) and wheat (Liang et al. 2014) and in the southern China F. asiaticum population from barley (Zhang et al. 2010).

The genetic structure of $F$. graminearum populations from wheat in the United States has been studied extensively. Zeller et al. (2004) reported low levels of population subdivision within $F$. graminearum and a homogeneous population in North America. However, subsequent studies reported substantial population subdivision correlated with trichothecene chemotype differences in the upper Midwestern United States and elsewhere in North America (Gale et al. 2007, 2011; Puri and Zhong 2010; Ward et al. 2008). Few studies have focused on the population genetic structure of $F$. graminearum from barley. Recently, isolates of $F$. graminearum from barley fields in 
North Dakota and Minnesota were collected and analyzed using variable number tandem repeat (VNTR) markers (Burlakoti et al. 2011). Low $F_{S T}$ between samples grouped according to the $3 \mathrm{ADON}$ or $15 \mathrm{ADON}$ chemotype suggested a minor influence of the chemotype on population subdivision. A similar study of the FHB population of $F$. asiaticum from barley in southern China did however present evidence for subdivision corresponding to chemotype composition (Zhang et al. 2010).

The objectives in this study were to (i) compare the population genetic structure of $F$. graminearum from barley and wheat in contemporaneous populations from the upper Midwestern United States, (ii) test the population subdivision of Fusarium graminearum from a barley-only population, and (iii) investigate whether isolates producing the novel trichothecene NX-2 are found in the barley population of $F$. graminearum.

\section{MATERIALS AND METHODS}

Fungal strains from barley and wheat. The strains of F. graminearum from barley used in a previous study (Burlakoti et al. 2011) were cultured from infected barley leaves obtained from North Dakota State University. A total of 247 F. graminearum isolates were recovered ( $n=110$ for the older population isolated from 1997 to 2000 and $n=137$ for the newer population isolated in 2008) and isolates were grouped by geographic location as Northern region, Central region, and Southern region (Table 1). Of the 262 $F$. graminearum isolates used in the previous study, 5 and 10 isolates were lost from the older and newer barley collections, respectively, due to missing or nonviable samples.

To compare the population genetic structure of $F$. graminearum from barley and wheat, contemporaneous strains of $F$. graminearum from wheat were also obtained from a previous study (Liang et al. $2014)$. For the older population $(n=110), F$. graminearum isolates were mainly collected from 1999 to 2000 and also were grouped as northern region (older wheat population from northern region, OldWN), central region (OldWC), and southern region (OldWS). However, for the newer population $(n=56)$ only isolates collected in southern region (NewWS) were available for 2006. The details of sampled counties and the number of isolates from each county are shown in Table 1. To balance sample size between wheat and barley isolates, only the counties in bold ( $n=146$, Table 1$)$ from the barley collection were used to compare with all isolates from wheat. These isolates from barley were also grouped according to three geographical regions: older northern region (older barley population from northern region, OldBN), older central region (OldBC), older southern region (OldBS), and newer southern region (NewBS). Culture conditions, preparation of mycelium, and DNA extraction of each isolate were performed as described previously (Gale et al. 2002).

Trichothecene profiling of $F$. graminearum populations from wheat and barley. The trichothecene chemotype of every $F$. graminearum isolate was determined using previously validated trichothecene chemotype polymerase chain reaction (PCR) assays. TRI3 and TRI12 multiplexes were used to distinguish 3ADON, 15ADON, and NIV chemotypes (Starkey et al. 2007; Ward et al. 2002). The TRII-ApoI enzyme combination was used to detect the novel trichothecene type, NX-2 (Liang et al. 2014). The PCR reactions, annealing temperature and program cycle for every primer set followed previous studies (Liang et al. 2014; Ward et al. 2008).

PCR-restriction fragment length polymorphism (RFLP) molecular genotyping. Ten pairs of PCR-RFLP primers designed in a previous study (Gale et al. 2011) were used to generate molecular datasets for population genetic analysis (Table 2 ). The amplification reactions were performed in $20-\mu$ l volumes with $2 \mu \mathrm{l}$ of 10× rTaq buffer (Takara Biotechnology, Dalian), $1.6 \mu \mathrm{l}$ of dNTP $(2.5 \mathrm{mM} / \mu \mathrm{l}), 20 \mathrm{pmol}$ of each primer, $0.5 \mathrm{U}$ of rTaq (Takara Biotechnology), and 20 ng of genomic DNA. Amplification was carried out in a Bio-Rad Peltier Thermal Cycler using the following program with different annealing temperatures (Table 2): initial denature for $2 \mathrm{~min}$ at $94^{\circ} \mathrm{C}$, followed by 30 cycles of denature at $94^{\circ} \mathrm{C}$ for $1 \mathrm{~min}$, different annealing temperature for $1 \mathrm{~min}$, extension at $72^{\circ} \mathrm{C}$ for $2 \mathrm{~min}$ and an additional extension at $72^{\circ} \mathrm{C}$ for $10 \mathrm{~min}$. Enzyme digestions were performed in $15-\mu$ l volumes using $10 \mu \mathrm{l}$ of the PCR end product above, $0.15 \mu \mathrm{l}$ of $5 \mathrm{U} / \mu \mathrm{l}$ of every restriction enzyme, $0.15 \mu \mathrm{l}$ of $100 \times$ BSA (if necessary, see Table 2 ), and sterile water added to bring the final volume to $15 \mu \mathrm{l}$. All restriction enzymes were incubated at $37^{\circ} \mathrm{C}$ for $2 \mathrm{~h}$ except Taq a, which was incubated at $65^{\circ} \mathrm{C}$ for $2 \mathrm{~h}$. PCR reactions were conducted in 96-well plates with a negative control (primer and water) and a positive control (primer plus DNA from strain PH-1 [NRRL31084]) in each

TABLE 1. Strains of Fusarium graminearum from barley and wheat fields in North Dakota and Minnesota

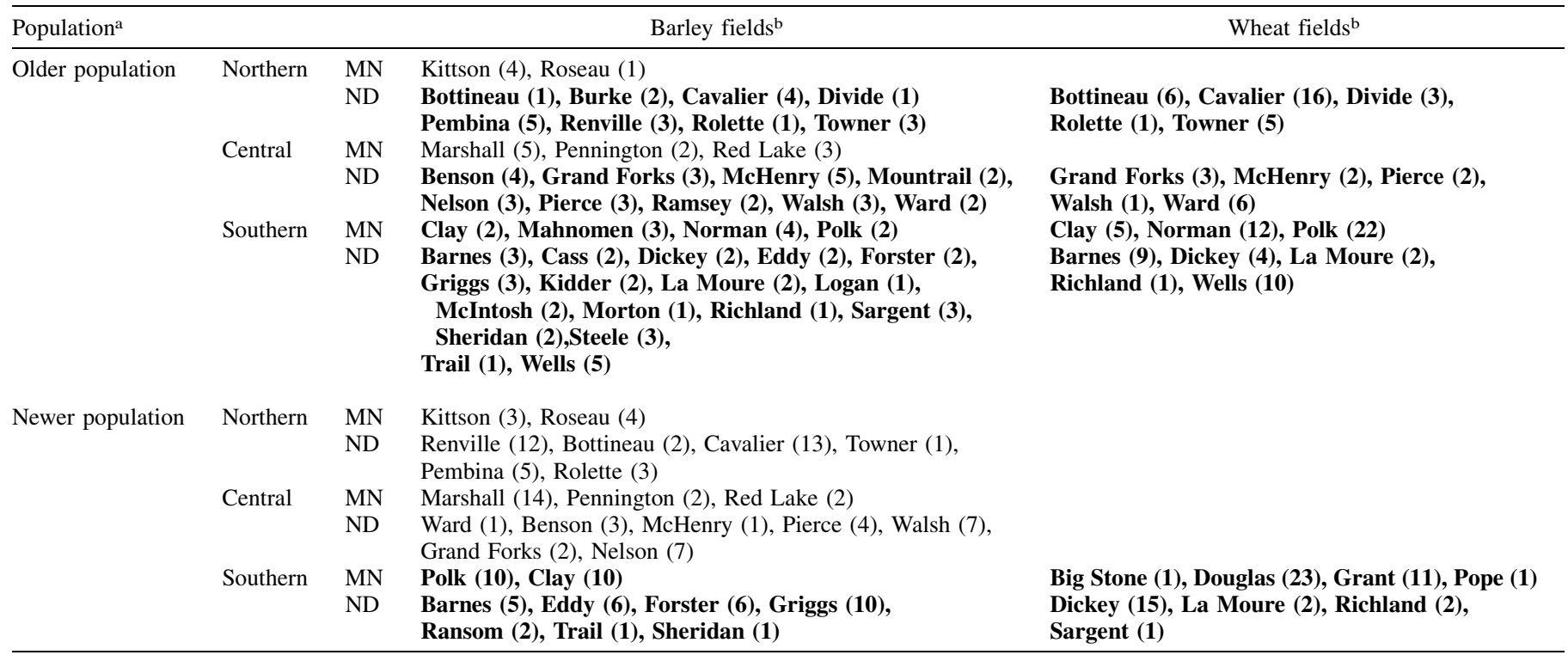

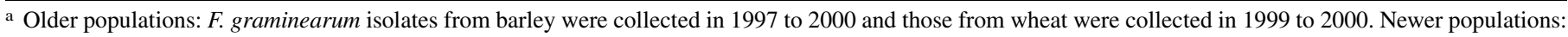
F. graminearum isolates from barley were collected in 2008 and those from wheat were collected in 2006.

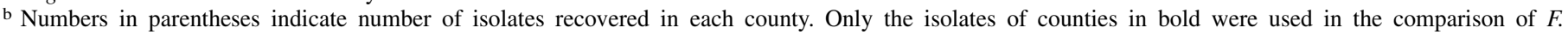
graminearum between wheat and barley populations.
} 
plate. Scoring was described in a previous study (Gale et al. 2011). Each specific pattern per locus was considered to be a different allele.

Population genetic analysis. For balancing the sample size and locations, only the strains collected from regions including both wheat and barley isolates (isolates in bold in Table 1) were used to compare genetic structure between collections arising from wheat and barley. The resulting collections were as follows: OldWN $(n=$ $31)$, OldWC $(n=14)$, OldWS $(n=65)$, NewWS $(n=56), \operatorname{OldBN}(n=$ $95)$, OldBC $(n=26)$, OldBS $(n=48)$, and NewBS $(n=51)$. The frequencies of distinct alleles at each locus and gene diversity were calculated in POPGENE 1.32 (Yeh et al. 1997). Distinct multilocus genotype $(G)$ and genotypic diversity $(G D)$ were calculated in each population using MULTILOCUS 1.3 software (Agapow and Burt 2001). Linkage disequilibrium $(L D)$ was assessed in MULTILOCUS

TABLE 2. Polymerase chain reaction-restriction fragment length polymorphism (PCR-RFLP) primer annealing temperature, relevant restriction enzymes, number of alleles, and allele frequency in Fusarium graminearum isolates from wheat and barley

\begin{tabular}{lcccccc}
\hline Primers & $\mathrm{T}\left({ }^{\circ} \mathrm{C}\right)$ & $\mathrm{RE}^{\mathrm{a}}$ & $\mathrm{AW}^{\mathrm{b}}$ & $\mathrm{FW}^{\mathrm{c}}$ & $\mathrm{AB}^{\mathrm{d}}$ & $\mathrm{FB}^{\mathrm{e}}$ \\
\hline $1389 / 1890$ & 57 & $\begin{array}{c}\text { HaeIII/ } \\
\text { BamHI }\end{array}$ & 2 & $0.271-0.723$ & 2 & $0.288-0.651$ \\
& & & & & \\
$1401 / 1402$ & 57 & HinfI & 5 & $0.006-0.608$ & 4 & $0.007-0.712$ \\
$1403 / 1404$ & 56 & HaeIII & 5 & $0.012-0.482$ & 4 & $0.007-0.548$ \\
$1407 / 1407$ & 56 & $\begin{array}{c}\text { HindIII/ } \\
\text { MspI }\end{array}$ & 4 & $0.006-0.620$ & 3 & $0.089-0.596$ \\
& & & & & \\
$1155 / 1156$ & 58 & HaeIII & 6 & $0.006-0.705$ & 4 & $0.007-0.774$ \\
$1415 / 1416$ & 57 & HaeIII & 5 & $0.024-0.741$ & 5 & $0.014-0.651$ \\
$1439 / 1440$ & 52 & HinfI & 6 & $0.012-0.253$ & 8 & $0.007-0.295$ \\
$1441 / 1442$ & 57 & TaqaI & 4 & $0.006-0.572$ & 5 & $0.007-0.582$ \\
$1449 / 1450$ & 57 & HinfI & 3 & $0.241-0.392$ & 5 & $0.007-0.438$ \\
$1457 / 1458$ & 58 & HaeIII & 4 & $0.078-0.620$ & 4 & $0.075-0.582$ \\
Total & & & 44 & & 44 &
\end{tabular}

a Restriction enzyme(s) used to detect polymorphisms in this amplicon.

b Number of distinct alleles for this locus in $F$. graminearum isolates from wheat.

c Allele frequencies for this PCR/RFLP locus in F. graminearum isolates from wheat.

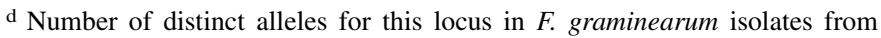
barley.

e Allele frequencies for this PCR/RFLP locus in F. graminearum isolates from barley.
1.3 using the loci-corrected index, $r D$. Genetic differentiations $(\Phi p t)$ among populations were estimated using Genalex 6.2 (Peakall and Smouse 2006). The statistical significance of $r D$ and $\Phi p t$ were assessed using 1,000 random permutations.

A Bayesian clustering method was used to test the population subdivision of $F$. graminearum strains from wheat and barley in STRUCTURE 2.1 software (Pritchard et al. 2000). All F. graminearum isolates from wheat $(n=166)$ and barley $(n=146)$ were assigned into $K$ populations with $K$ ranging from 1 to 10 based on their multilocus haplotypes generated from 10 pairs of PCR-RFLP primers. The admixture model and correlated alleles were used. Each $K$ was run for 10,000 iterations of the Monte Carlo Markov Chain (MCMC) scheme with a 1,000 burn-in period. Other settings were as recommended by default. The number of populations $(K)$ best representing the observed data was evaluated by $\Delta K$ as proposed by Evanno et al. (2005). In order to test the potential of population subdivision in the barley-only collection, all recovered $F$. graminearum strains from barley in previous study (Burlakoti et al. 2011) $(n=247)$ were rerun in STRUCTURE software using the same settings as above.

In order to compare values for pair-wise genetic identity $(I)$ and gene flow $(\mathrm{Nm})$ estimated in the previous study (Burlakoti et al. 2011) in which subpopulation was grouped based on trichothecene chemotype (3ADON and 15ADON), values of $I$ and $N m$ were recalculated for the current study using populations classified based on chemotype alone as in the previous study (Burlakoti et al. 2011) or based on Bayesian assignment obtained using the STRUCTURE software. POPGENE 1.32 (Yeh et al. 1997) was used to calculate $I$, and $N m$ was estimated by Genalex 6.2 (Peakall and Smouse 2006).

\section{RESULTS}

Trichothecene profiling. The frequency of $3 \mathrm{ADON}$ producing strains was compared between isolations obtained from wheat and barley. Strains were chosen to reflect similar spatial and temporal collections; only isolates obtained from sampled counties indicated in bold in Table 1 were used. Four 3ADON producing strains were detected in the older barley population $(n=95)$ with a frequency of $4.2 \%$, which was not significantly different $(P=$ $0.52)$ from the frequency $(5.5 \%)$ of $3 \mathrm{ADON}$ producing strains in the older wheat population $(n=110)$ (Table 3$)$. However, the frequency of $3 \mathrm{ADON}$ producing strains in the newer barley population

TABLE 3. Trichothecene profile, genetic diversity, distinct genotypes, gene diversity, and linkage disequilibrium analysis of eight geographic and temporal subpopulations of Fusarium graminearum from wheat and barley

\begin{tabular}{|c|c|c|c|c|c|c|c|c|c|}
\hline \multirow[b]{2}{*}{ Population $^{\mathrm{a}}$} & \multirow[b]{2}{*}{$N^{\mathrm{b}}$} & \multicolumn{3}{|c|}{ Trichothecene profile } & \multirow[b]{2}{*}{$G^{\mathrm{c}}$} & \multirow[b]{2}{*}{$G D^{\mathrm{d}}$} & \multirow[b]{2}{*}{$H^{\mathrm{e}}$} & \multirow[b]{2}{*}{$r D^{\mathrm{f}}$} & \multirow[b]{2}{*}{ Rangeg } \\
\hline & & $15 \mathrm{ADON}$ & $3 \mathrm{ADON}$ & $\mathrm{NX}-2$ & & & & & \\
\hline OldBN & 20 & 20 & 0 & 0 & 20 & 1.000 & $0.471 \pm 0.166$ & $0.037, P=0.028$ & $-0.040-0.067$ \\
\hline OldBC & 27 & 26 & 1 & 0 & 27 & 1.000 & $0.526 \pm 0.125$ & $0.029, P=0.022$ & $-0.034-0.048$ \\
\hline NewBS & 51 & 36 & 15 & 0 & 46 & 0.996 & $0.537 \pm 0.114$ & $0.073, P<0.001$ & $-0.024-0.026$ \\
\hline Total & 146 & 127 & 19 & 0 & 124 & 0.997 & $0.542 \pm 0.119$ & & \\
\hline NewWS & 56 & 30 & 24 & 2 & 50 & 0.994 & $0.533 \pm 0.156$ & $0.055, P<0.001$ & $-0.017-0.022$ \\
\hline Total & 166 & 132 & 30 & 4 & 148 & 0.998 & $0.556 \pm 0.118$ & & \\
\hline
\end{tabular}

a $\mathrm{OldB}=$ isolates collected from the older barley population; OldW $=$ isolates collected from the older wheat population; NewB $=$ isolates collected from the newer barley population; NewW = isolates collected from the newer wheat population. The last letters $(\mathrm{N}, \mathrm{C}$, and $\mathrm{S}$ ) indicate isolates representing northern, central, or southern region, respectively (Fig. 1).

b Number of isolates.

c Number of distinct genotypes $(G)$.

d Genotypic diversity $(G D)$ in each population calculated as $G D=(n / n-1)\left(1-\Sigma p i^{2}\right)$, where $p i$ is the frequency of the $i$ th genotype and $n$ is the number of individuals sampled.

e Mean \pm standard error of the mean gene diversity within each population, calculated based on Nei's genetic distance (Nei 1973).

${ }^{\mathrm{f}}$ Measure of linkage disequilibrium from observed dataset.

g $r D$ range for 1,000 random permutations in MULTILOCUS 1.31 (Agapow and Burt 2001). 
(NewBS) $(29.4 \%)(n=51)$ was significantly lower $(P=0.001)$ than the frequency $(42.9 \%)$ in the newer wheat population (NewWS) $(n$ $=56$ ). No NX-2 producing strains were detected among the 247 isolates from barley. In contrast, two NX-2 producing strains were isolated from wheat in the older collection (Clay County, Minnesota) and another two were isolated from the newer wheat collection (Douglas County, Minnesota).

The geographic distribution of $3 \mathrm{ADON}$ producing strains in older wheat and barley collections was similar, with 3ADON strains mainly isolated from the border counties between Minnesota and North Dakota except one strain (KB1228, in McHenry County) isolated from the central region in the older barley collections (Fig. $1)$. Due to the low number of $3 \mathrm{ADON}$ isolates in both the older wheat $(n=6)$ and barley $(n=4)$ (Table 3$)$ collections as well as the limited sampling of counties (Table 1) in the newer wheat population, the geographic distribution of $3 \mathrm{ADON}$ strains was analyzed only in the newer barley collection. A latitudinal cline was identified in which the frequency of $3 \mathrm{ADON}$ producing strains was highest in the northern region (49\%), decreasing to $40 \%$ in the central region $(P=$ 0.068 , Fisher's test), and significantly decreasing to $29 \%$ in the southern region $(P=0.003)$ (Fig. 1).

Population genetic analysis with PCR-RFLP markers. Ten pairs of PCR-RFLP primers used in this study generated the same total number of alleles $(n=44)$ in wheat and barley populations (Table 2). The number of alleles identified at these loci ranged from two to eight with a slight variation between wheat and barley populations. Allele frequencies at each locus ranged from 0.006 to 0.774 (Table 2). A total of 122 distinct genotypes were detected in the combined older and newer barley population $(G=$
$0.85)$, which was similar to the genotypic diversity in the wheat population $(G=0.89)$. High $G D$ and similar $H$ were observed in both barley and wheat populations (Table 3). Inference from $r D$ values suggested random mating within all older wheat and barley subpopulations (all $P$ values $>0.05$ ) but not within newer wheat and barley subpopulations (both $P$ values $<0.001$ ) based on 1,000 random permutations in linkage disequilibrium tests (Table 3 ).

Comparison of genetic structure between wheat and barley populations. In total, genotypes of $146 \mathrm{~F}$. graminearum isolates from barley and 166 isolates from wheat were combined to test for population structure. In previous studies, two $F$. graminearum populations were identified from wheat isolates in the upper Midwest United States (Gale et al. 2007; Liang et al. 2014): NA1 (previously called the MW 15ADON population) and NA2 (previously called the UMW 3ADON population). Using STRUCTURE to test population models for the combined genotypes from barley and wheat, the $\log$ likelihood was maximized when $K=2(\operatorname{LnP}(\mathrm{D})=-2735.13)$ (Supplementary Table S1). Most 3ADON strains (84.5\%) from wheat and all $3 \mathrm{ADON}$ strains $(100 \%)$ from barley were placed together into the previously reported NA2 population with high membership fraction $\mathrm{Q}=0.97 \pm 0.03$ (Fig. 2). Similarly, $81.3 \%$ of $15 \mathrm{ADON}$ strains from wheat and $91.3 \% 15 \mathrm{ADON}$ strains from barley were assigned together to the NA1 population with $\mathrm{Q}=0.96 \pm$ 0.04 (Fig. 2). These results indicate the barley population of F. graminearum is characterized by population subdivision and these subdivisions correspond to the previously observed NA1 and NA2 populations. NA1 contains the largest proportion of $15 \mathrm{ADON}$ isolates and NA2 contains the largest proportion of $3 \mathrm{ADON}$ isolates, regardless of host origin.

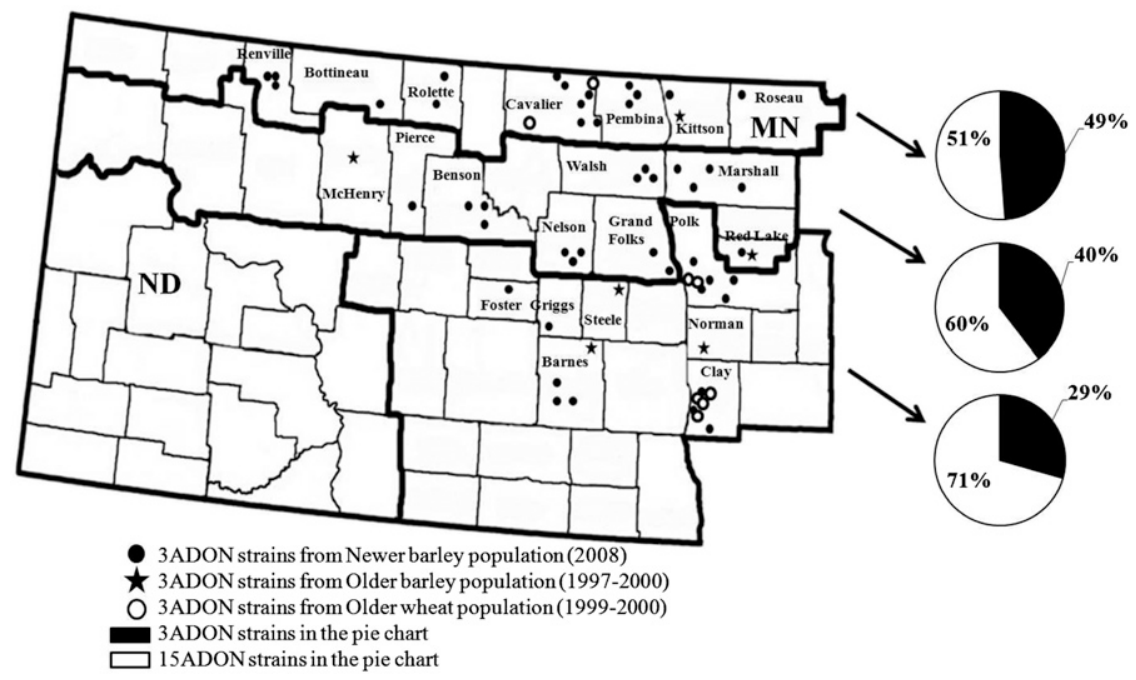

Fig. 1. Distribution of $3 \mathrm{ADON}$ chemotype isolates from the barley and wheat collections from the previously defined northern, central, and southern regions (Burlakoti et al. 2011). Only frequencies of 3ADON strains from the Newer barley population are shown in the pie charts because few $3 \mathrm{ADON}$ isolates were found in the Older barley $(n=4)$ and Older wheat $(n=6)$ collections and only limited sampling locations among these regions were done for the Newer wheat collections.

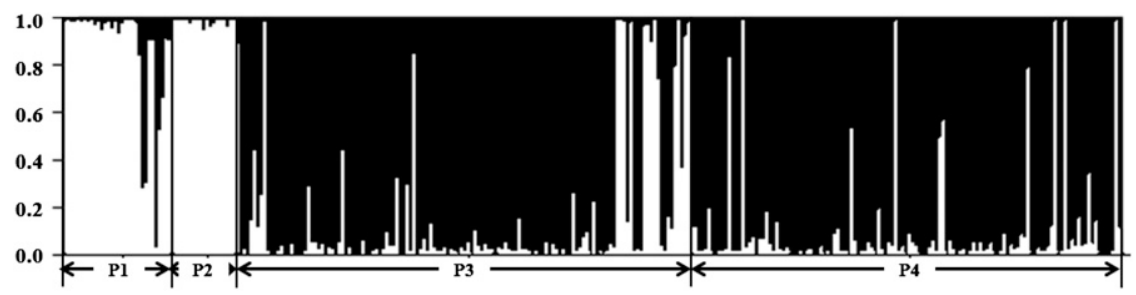

Fig. 2. Population structure of Fusarium graminearum based on 10 polymerase chain reaction (PCR)-restriction fragment length polymorphism data for 166 isolates from wheat and 146 isolates from barley. All isolates were assigned into two populations, NA1 population (black) and NA2 population (white). Isolates within $\mathrm{P} 1$ and $\mathrm{P} 2$ ranges are 3ADON producing strains of $F$. graminearum based on TRI-based multiplex PCR from wheat and barley, respectively. Isolates within $\mathrm{P} 3$ and $\mathrm{P} 4$ ranges are $15 \mathrm{ADON}$ producing strains from wheat and barley, respectively. 
When analyses were limited to the barley isolates recovered from the previous study, $247 \mathrm{~F}$. graminearum isolates ( $n=110$ for the older barley population and $n=137$ for the newer barley population) were also assigned into two genetic groups in STRUCTURE $(K=2$, $\mathrm{LnP}(\mathrm{D})=-1929.04)$ (Supplementary Table S2). In addition, this subdivision was also correlated to trichothecene chemotype with $98.3 \%$ of $3 \mathrm{ADON}$ producing strains having high membership fraction $(\mathrm{Q})>0.9$ (average $\mathrm{Q}=0.97 \pm 0.04$ [standard deviation]) assigned into the white partition (NA2 population) illustrated in Figure 3 , and $85.1 \%$ of $15 \mathrm{ADON}$ strains with $\mathrm{Q}>0.9$ (average $\mathrm{Q}=$ $0.97 \pm 0.02$ ) assigned into the black partition (NA1 population) in Figure 3 . These results indicate that the population subdivision among the barley isolates wasn't an artifact owing to the inclusion of the wheat isolates in the Bayesian analyses described above, but reflect a similar subdivision of $F$. graminearum populations across the two hosts.

To determine whether potential differences occur for the NA1 and NA2 partitions between wheat and barley populations, pair-wise genetic differentiation $(\Phi p t)$ among NA1 and NA2 subpopulations in two sampling periods within wheat and within barley were compared. All pair-wise $\Phi p t$ subpopulations combinations were significant except Older NA2 and Newer NA2 $(\Phi p t=0.018, P=0.269)$ (Table 4), demonstrating that subpopulations defined based on Bayesian assignment results represented genetically differentiated populations. Interestingly, the $\Phi p t$ values between NA1 and NA2 subpopulations were higher among barley isolates (Older: $\Phi p t=$ 0.244 and Newer: $\Phi p t=0.378)$ than those from wheat (Older: $\Phi p t=$ 0.141 and Newer: $\Phi p t=0.249)$ (Table 4). These results suggest that the NA1 and NA2 populations on barley are less genetically integrated than on wheat.

Analysis of potential recombinant genotypes. The Bayesian assignment result in STRUCTURE suggested population subdivision was closely related with chemotype, but two $15 \mathrm{ADON}$ strains from barley, nine $15 \mathrm{ADON}$ and two $3 \mathrm{ADON}$ strains from wheat were weakly $(0.5<\mathrm{Q}<0.8)$ assigned to NA1 population or NA2 population. In addition, 9 and $1615 \mathrm{ADON}$ strains with $\mathrm{Q}>$ 0.5 , from barley and wheat, respectively, were assigned to the NA2 population and three $3 \mathrm{ADON}$ strains from wheat were assigned to the NA1 population. These assignments suggested introgression between the NA1 and NA2 populations in both wheat and barley populations. Isolates with $0.5<\mathrm{Q}<0.8$ and $\mathrm{Q}>0.5$ but having a trichothecene type contrary to the predominant chemotype of the genetic subpopulation assigned were defined as admixed strains. For example, KB1307 is a $15 \mathrm{ADON}$ producing strain and although at $\mathrm{Q}=0.989$, it was assigned into NA2 which predominantly consists of 3ADON chemotype strains (Table 4). Thus, 41 admixed isolates were obtained from $312 \mathrm{~F}$. graminearum isolates of wheat and barley populations (Table 4). Among 41 admixed isolates, 30 isolates (18.1\% of wheat strains) were from the wheat population while 11 isolates (7.5\% of barley strains) were from the barley population. For the Old period, the admixture proportion (the frequency of admixed isolates among all isolates) in the wheat population
$(10.9 \%)$ was not even twice as much as in the barley population $(6.3 \%)$. However, in the New period the gap increased, with the admixture proportion of the wheat population $(32.1 \%)$ being more than three times that in the barley population (9.8\%) (Table 4).

All 11 admixed isolates from the barley population were $15 \mathrm{ADON}$ producing strains, and their membership fraction $(\mathrm{Q})$ of the genetic materials derived from NA2 population ranged from 0.345 to 0.989 with six $(55 \%)$ isolates assigned into NA2 at Q > 0.8 (Table 5). No $3 \mathrm{ADON}$ admixed isolates in the barley population were detected suggesting unidirectional gene introgression between NA1 and NA2 in the barley population. In contrast, five $3 \mathrm{ADON}$ admixed isolates ( $16.7 \%$ of total admixed isolates in wheat population) were detected in NA1 of the wheat population with Q from 0.342 to 0.967 . Nevertheless, most of the admixed isolates in wheat population were $15 \mathrm{ADON}$ strains, and their proportion of genetic material derived from the NA2 population ranged from 0.250 to 0.990 with 14 isolates $(56 \%)$ assigned into NA2 with Q $>0.8$. Thus, the presumptive gene introgression between NA1 and NA2 in wheat the population appears bidirectional. Meanwhile, these results suggest a potential bias in the direction of gene introgression, as $15 \mathrm{ADON}$ isolates with a NA2 genetic background were significantly more common ( $F$ test; $P=$ $3.8 \times 10^{-5}$ for the barley population and $P=1 \times 10^{-5}$ for the wheat population) than the $3 \mathrm{ADON}$ isolates with a NA1 genetic background.

Population level analysis in the barley population. Burlakoti et al. (2011) found high $\mathrm{Nm}(\mathrm{Nm}=23.26)$ and low genetic differentiation $\left(F_{S T}=0.02\right)$ between $3 \mathrm{ADON}$ and $15 \mathrm{ADON}$ populations using VNTR markers suggesting minor influence of chemotypes on $F$. graminearum population subdivision among barley isolates. Based on PCR-RFLP markers, we recalculated overall gene flow $(\mathrm{Nm})$ and genetic differentiation ( $\Phi p t$, equivalent to $F_{S T}$ ) between $3 \mathrm{ADON}(n=59)$ and 15ADON $(n=188)$ strains as in Burlakoti et al. (2011). Contrary to the previous study, we found that $\mathrm{Nm}$ was only 0.63 and $\Phi p t$ was high and significant $(0.44, P=0.001)$. These results suggest limited gene flow and high genetic differentiation between $3 \mathrm{ADON}$ and $15 \mathrm{ADON}$ isolates. Correspondingly, analysis of molecular variance revealed $44 \%$ genetic differentiation between isolates grouped by chemotype, which was much higher than the value (3\%) reported previously (Burlakoti et al. 2011).

Due to gene introgression, isolates grouped solely by chemotype do not accurately reflect the population structure of the barley isolates. Subpopulations as based on time of strain collection and Bayesian assignment resulted in the following: Newer NA2 $(n=$ $61)$, Newer NA1 $(n=76)$, Older NA2 $(n=8)$, and Older NA1 $(n=$ 102). Pair-wise $N m$ and $I$ were calculated for these partitions to depict the picture of population structure after some level of introgression. To compare with the results of Burlakoti et al. (2011), pair-wise $N m$ and $I$ were also recalculated for subpopulations grouped by chemotype alone as in the previous study (Burlakoti et al. 2011): Newer 3ADON $(n=53)$, Newer 15ADON $(n=84)$, Older 3ADON $(n=6)$, and Older 15ADON $(n=104)$. Calculations for the Older NA2 and the Older $3 \mathrm{ADON}$ were not conducted due to small sample size. Compared with the previous study (Burlakoti et al.

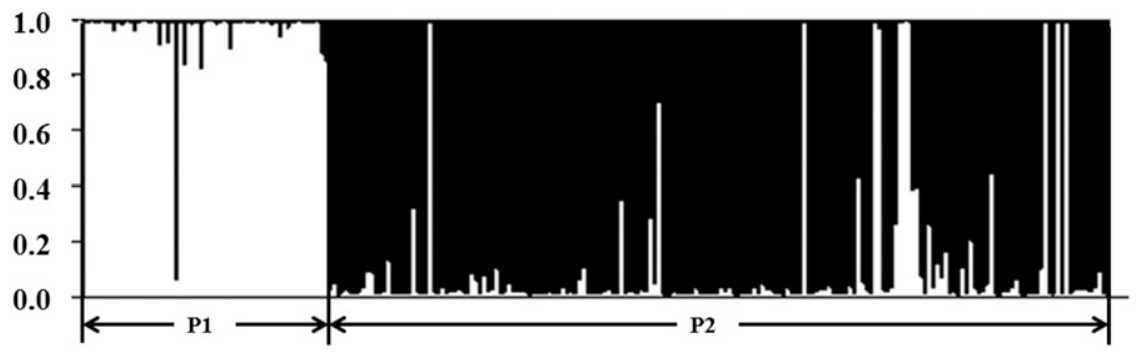

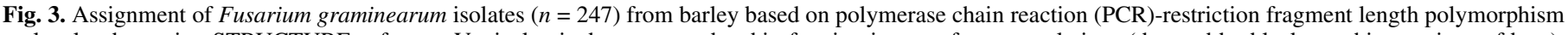

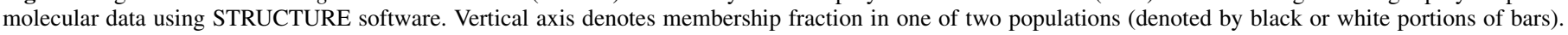

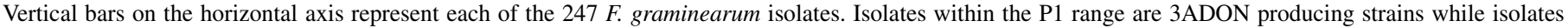
within the P2 range are 15ADON producing strains as determined by the TRI-based multiplex PCR test. 
2011), our calculations of pair-wise $\mathrm{I}$ and $\mathrm{Nm}$ between subpopulations grouped by chemotype were significantly reduced between Newer $3 \mathrm{ADON}$ and Newer $15 \mathrm{ADON}$ as well as between Newer $3 \mathrm{ADON}$ and Older 15ADON subpopulations $(P=0.014$ for $I$ and $P=0.036$ for $N m)$. Meanwhile, our values for $I(0.98)$ and $N m(36.42)$ between Newer 15ADON and Older 15ADON subpopulations were higher than previously reported ( 0.87 for $I$ and 28.71 for $N m$ ) (Table 6). When subpopulations were grouped based on Bayesian assignment, pair-wise $I$ values were similar to analogous comparisons based on chemotype and $\mathrm{Nm}$ values were greater between Newer NA1 and Older NA1 (Table 6).

\section{DISCUSSION}

A previous study of $F$. graminearum strains from barley in the upper Midwestern United States concluded that population subdivision was not evident among the collected strains (Burlakoti et al. 2011). These findings were noteworthy because other studies consisting largely of strains derived from wheat in the northern United States and Canada found clear evidence of persistent population subdivision strongly, but not absolutely, correlated with trichothecene chemotype (Gale et al. 2007; Liang et al. 2014; Ward et al. 2008). The findings of Burlakoti et al. (2011) thus suggested that population dynamics of the pathogen could be quite different between barley and wheat. To test for differences in population structure between isolates obtained from wheat and from barley, we tested all available (247 of 262) barley isolates utilized in the previous study (Burlakoti et al. 2011). Of those, 146 isolates from barley were matched with 166 isolates obtained from wheat at similar times and locations (Table 1).

As Burlakoti et al. (2011) previously observed, the current study also detected a greatly increased frequency of 3ADON strains from the older period (1997 to 2000) to the newer period (2008). We additionally observed an increased occurrence of 3ADON strains in the wheat population compared with the barley population. However, unlike the previous study (2011), we found evidence for significant population subdivision associated with trichothecene chemotype differences among both barley and wheat populations, which is consistent with most previous analyses of $F$. graminearum populations from wheat in this region (Abramson et al. 2001; Gale et al. 2007; Liang et al. 2014; Ward et al. 2008). Because Burlakoti et al. (2011) and the current study used the same barley isolates, what is the basis for our different findings?

The difference between our work, which uses PCR-RFLP genetic markers, and the work of Burlakoti et al. (2011), which uses VNTR markers, apparently does not result from differences in the markers used. Ward et al. (2008), Puri and Zhong (2010), and Bec et al. (2014) all documented significant population structure associated with chemotype differences on the basis of VNTR markers. Puri and Zhong (2010) also found significant structure using amplified fragment length polymorphic markers, though $F_{S T}$ was lower than with VNTR. Therefore, we believe our differences with the previous work are not attributable to the different genetic markers used. Because Burlakoti et al. (2011) do not adequately detail the method by which $F_{S T}$ was calculated for their study, it is impossible to determine whether they have used an appropriate metric for determining $F_{S T}$ from microsatellite data.

One other contemporary study fails to find population subdivision associated with chemotype. Guo et al. (2008) used sequence related amplified polymorphism (SRAP) markers for analyzing $F$. graminearum collections from Manitoba. SRAP markers have shortcomings if they have not been unambiguously assigned to specific genetic loci and due to the fact that they may produce both dominant and codominant markers, making interpretation of data challenging (Wang et al. 2011). Further, Guo et al. (2008) did not use $F_{S T}$ to evaluate population level differences and so their results are not directly comparable to other contemporary studies of population structure in Canada. In contrast, Ward et al. (2008) used VNTR markers to document significant population structure associated with trichothecene chemotype in Manitoba using isolates collected from roughly the same time period as Guo et al. (2008). Ward et al. (2008) included an evaluation of $F_{S T}$ as well as a Bayesian assessment of admixture and population assignment.

Comparison of chemotype profiles of $F$. graminearum strains revealed that $15 \mathrm{ADON}$ was the most frequently isolated chemotype from both barley and wheat. However, 3ADON producing strains may have a higher rate of dissemination and spread on wheat than on

TABLE 4. Admixed isolates from wheat and barley populations based on Bayesian assignment result

\begin{tabular}{|c|c|c|c|c|c|}
\hline \multirow[b]{2}{*}{ Population } & \multirow[b]{2}{*}{$\begin{array}{l}\text { Admixture } \\
\text { proportion }^{\mathrm{b}}\end{array}$} & \multirow[b]{2}{*}{$\begin{array}{l}\text { Isolate } \\
\text { name }\end{array}$} & \multirow[b]{2}{*}{$\begin{array}{c}\text { Trichothecene } \\
\text { type }\end{array}$} & \multicolumn{2}{|c|}{$\begin{array}{l}\text { Membership } \\
\text { fraction }(\mathrm{Q})^{\mathrm{a}}\end{array}$} \\
\hline & & & & $\begin{array}{c}\text { NA1 } \\
\text { population }\end{array}$ & $\begin{array}{c}\text { NA2 } \\
\text { population }\end{array}$ \\
\hline \multirow{6}{*}{$\begin{array}{l}\text { Older } \\
\text { barley } \\
\text { population } \\
(n=95)\end{array}$} & \multirow[t]{6}{*}{$6.3 \%$} & KB1187 & $15 \mathrm{ADON}$ & 0.504 & 0.496 \\
\hline & & KB1282 & $15 \mathrm{ADON}$ & 0.470 & 0.530 \\
\hline & & KB1319 & $15 \mathrm{ADON}$ & 0.429 & 0.571 \\
\hline & & KB1305 & $15 \mathrm{ADON}$ & 0.165 & 0.835 \\
\hline & & KB1233 & $15 \mathrm{ADON}$ & 0.012 & 0.988 \\
\hline & & KB1307 & $15 \mathrm{ADON}$ & 0.011 & 0.989 \\
\hline \multirow{5}{*}{$\begin{array}{l}\text { Newer } \\
\text { barley } \\
\text { population } \\
(n=51)\end{array}$} & \multirow[t]{5}{*}{$9.8 \%$} & 253ND6 & $15 \mathrm{ADON}$ & 0.655 & 0.345 \\
\hline & & 22MN1 & $15 \mathrm{ADON}$ & 0.209 & 0.791 \\
\hline & & 212ND5 & $15 \mathrm{ADON}$ & 0.013 & 0.987 \\
\hline & & 215ND5 & $15 \mathrm{ADON}$ & 0.012 & 0.988 \\
\hline & & 231ND5 & $15 \mathrm{ADON}$ & 0.010 & 0.990 \\
\hline Subtotal & $7.5 \%$ & & & & \\
\hline \multirow{12}{*}{$\begin{array}{l}\text { Older } \\
\text { wheat } \\
\text { population } \\
(n=110)\end{array}$} & \multirow[t]{12}{*}{$10.9 \%$} & $99-185$ & $15 \mathrm{ADON}$ & 0.708 & 0.292 \\
\hline & & $00-836$ & $15 \mathrm{ADON}$ & 0.750 & 0.250 \\
\hline & & $00-800$ & $15 \mathrm{ADON}$ & 0.739 & 0.261 \\
\hline & & $00-544$ & $15 \mathrm{ADON}$ & 0.701 & 0.299 \\
\hline & & $00-677$ & $15 \mathrm{ADON}$ & 0.675 & 0.325 \\
\hline & & $00-781$ & $15 \mathrm{ADON}$ & 0.564 & 0.436 \\
\hline & & $00-834$ & $15 \mathrm{ADON}$ & 0.561 & 0.439 \\
\hline & & 00-619 & $15 \mathrm{ADON}$ & 0.155 & 0.845 \\
\hline & & $00-810$ & $15 \mathrm{ADON}$ & 0.101 & 0.899 \\
\hline & & $00-795$ & $15 \mathrm{ADON}$ & 0.018 & 0.982 \\
\hline & & $00-556$ & $3 \mathrm{ADON}$ & 0.695 & 0.305 \\
\hline & & $00-552$ & $3 \mathrm{ADON}$ & 0.719 & 0.281 \\
\hline \multirow{18}{*}{$\begin{array}{l}\text { Newer } \\
\text { wheat } \\
\text { population } \\
(n=56)\end{array}$} & \multirow[t]{18}{*}{$32.1 \%$} & 06-217 & $15 \mathrm{ADON}$ & 0.776 & 0.224 \\
\hline & & 06-180 & $15 \mathrm{ADON}$ & 0.635 & 0.365 \\
\hline & & 06-158 & $15 \mathrm{ADON}$ & 0.259 & 0.741 \\
\hline & & 06-176 & $15 \mathrm{ADON}$ & 0.205 & 0.795 \\
\hline & & 06-151 & $15 \mathrm{ADON}$ & 0.106 & 0.894 \\
\hline & & 06-191 & $15 \mathrm{ADON}$ & 0.077 & 0.923 \\
\hline & & $06-138$ & $15 \mathrm{ADON}$ & 0.035 & 0.965 \\
\hline & & $06-148$ & $15 \mathrm{ADON}$ & 0.035 & 0.965 \\
\hline & & 06-128 & $15 \mathrm{ADON}$ & 0.021 & 0.979 \\
\hline & & 06-198 & $15 \mathrm{ADON}$ & 0.021 & 0.979 \\
\hline & & 06-122 & $15 \mathrm{ADON}$ & 0.017 & 0.983 \\
\hline & & $06-246$ & $15 \mathrm{ADON}$ & 0.011 & 0.989 \\
\hline & & $06-247$ & $15 \mathrm{ADON}$ & 0.011 & 0.989 \\
\hline & & 06-179 & $15 \mathrm{ADON}$ & 0.011 & 0.989 \\
\hline & & 06-154 & $15 \mathrm{ADON}$ & 0.010 & 0.990 \\
\hline & & $06-163$ & $3 \mathrm{ADON}$ & 0.341 & 0.659 \\
\hline & & $06-142$ & $3 \mathrm{ADON}$ & 0.476 & 0.524 \\
\hline & & $06-140$ & 3ADON & 0.967 & 0.033 \\
\hline
\end{tabular}

Subtotal

$18.1 \%$

a Membership fraction (Q) denotes the percent of possibility to each population corresponding to NA1 and NA2 as defined previously (Liang et al. 2014).

b Admixture proportion $=$ number of admixed isolates $/$ the total number of isolates in this population. Admixed isolates are those with $15 \mathrm{ADON}$ and 3ADON chemotypes corresponding to NA1 and NA2 at $0.5<\mathrm{Q}<0.8$ respectively and those with $15 \mathrm{ADON}$ and $3 \mathrm{ADON}$ chemotypes assigned into NA2 and NA1 populations at Q $>0.5$, respectively. 
barley during both the old and new sampling periods. One possible explanation for the differential ability to spread could be the differences in the infection processes of $F$. graminearum on wheat and barley. On wheat, after initial infection the fungus readily spreads within the spike but such spread rarely occurs in barley (Jansen et al. 2005). Additionally, differences in sampling locations should also be considered. Sixteen isolates out of twenty-four 3ADON strains were collected from Douglas and Grant Counties, which were not included in the barley population sampling. Although we attempted to match temporal and geographic samplings from the two hosts, this was not always possible given the retrospective nature of the analyses, and additional studies of closely matched isolate collections are needed to further evaluate these potential host-specific differences in trichothecene chemotype frequencies.

The novel trichothecene type, NX-2, was detected among isolates from wheat but not from barley collected over a similar period of time. The absence of NX-2 isolates from the barley collection could reflect some difference in host-specific adaptation, either directly associated with this chemotype or with the NA2 genetic background in which the NX-2 chemotype was observed. However, the absence of NX-2 isolates among the barley population is not inconsistent with the very low frequency $(2.4 \%)$ of such isolates among the collection from wheat, and may simply reflect sampling error. However, the fact that NX-2 isolates were detected both in older and newer collections suggests that the NX-2 chemotype has persisted for some time and that strains capable of producing other unique toxins may remain undetected at low frequency.

In accord with previous studies, an increase in frequency of $3 \mathrm{ADON}$ isolates of $F$. graminearum was detected in current wheat and barley collections. The increasing frequency of $3 \mathrm{ADON}$ strains was first reported for isolations from wheat in Canada (Ward et al. 2008). Based on observations implying greater fitness for $3 \mathrm{ADON}$ isolates associated with NA2 including higher virulence, significantly more trichothecene accumulation, higher growth rates, and greater conidia production (Burlakoti et al. 2011; Foroud et al. 2012; Gilbert et al. 2010; Puri and Zhong 2010; Von der Ohe et al. 2010; Vujanovic et al. 2012; Ward et al. 2008), authors have speculated that such enhanced fitness may have caused the increasing frequency of 3ADON strains in North America. Recently however, Spolti et al. (2014) noted that for isolates in New York State, no fitness attributes of $3 \mathrm{ADON}$ isolates over 15ADON isolates were detected; these strains however were not assigned to genetic population. The gradient of decreasing frequency of $3 \mathrm{ADON}$ isolates from east to west in Canada was interpreted as migration of a newly introduced $3 \mathrm{ADON}$ population (corresponding to the NA2 population described here) (Liang et al. 2014). Indeed, the frequency of $3 \mathrm{ADON}$ chemotype strains increased greatly in the western provinces of Manitoba and Saskatchewan between the years of 1998 and 2004 (Ward et al. 2008). Schmale et al. (2011) evaluated the trichothecene type of $998 \mathrm{~F}$. graminearum isolates collected in the eastern United States in 2006 and found an increasing frequency of 3ADON strains from south to north with highest frequency $(15.4 \%)$ found in New York State and the lowest $(0.5 \%)$ in North Carolina. This latitudinal cline in the eastern United States combined with a similar higher frequency of 3ADON chemotype strains toward the northern upper Midwestern United States suggest a national trend perhaps indicating movement of the NA2 population from Canada into the United States.

To compare the genetic structure detected within $F$. graminearum populations in the current study with the previous study, isolates

TABLE 5. Pair-wise genetic differentiation ( $\Phi p t^{\mathrm{a}}$, below diagonal) and their probability (above diagonal) estimates among NA1 and NA2 subpopulations of Fusarium graminearum based on STRUCTURE 2.1 from wheat $(n=166)$ and barley $(n=146)$ populations

\begin{tabular}{|c|c|c|c|c|c|c|c|c|}
\hline \multirow[b]{3}{*}{ Population } & \multicolumn{4}{|c|}{ Wheat population ${ }^{\mathrm{b}}$} & \multicolumn{4}{|c|}{ Barley population ${ }^{\mathrm{b}}$} \\
\hline & Older NA1 & Older NA2 & Newer NA1 & Newer NA2 & Older NA1 & Older NA2 & Newer NA1 & Newer NA2 \\
\hline & $\overline{(n=101)}$ & $(n=9)$ & $(n=20)$ & $(n=36)$ & $(n=86)$ & $(n=9)$ & $(n=32)$ & $(n=19)$ \\
\hline Older NA2 & 0.141 & $\ldots$ & 0.001 & 0.001 & 0.244 & $\ldots$ & 0.001 & 0.269 \\
\hline Newer NA1 & 0.242 & 0.307 & $\ldots$ & 0.001 & 0.014 & 0.243 & $\ldots$ & 0.001 \\
\hline Newer NA2 & 0.311 & 0.314 & 0.249 & $\ldots$ & 0.361 & 0.018 & 0.378 & $\ldots$ \\
\hline
\end{tabular}

${ }^{a} \Phi p t$, an analog of $F_{S T}$, is also the estimate of population genetic differentiation when binary and haploid data are analyzed.

b Older denotes the isolates collected from the barley population in 1997 to 2000 and from the wheat population in 1999 to 2000; Newer denotes the isolates collected from the barley population in 2008 and from the wheat population in 2006. NA1 and NA2, formerly known as MW15ADON and UMW3ADON populations (Gale et al. 2007), respectively, based on STRUCTURE 2.1. Isolates were placed in the NA2 or NA1 populations with membership fraction Q > 0.5 regardless of trichothecene type. Probability of $\Phi p t$ value was determined by 1,000 random permutations.

TABLE 6. Pair-wise comparisons of gene flow (above diagonal) and genetic identity (below diagonal) between barley subpopulations grouped solely by trichothecene type or by Bayesian assignment

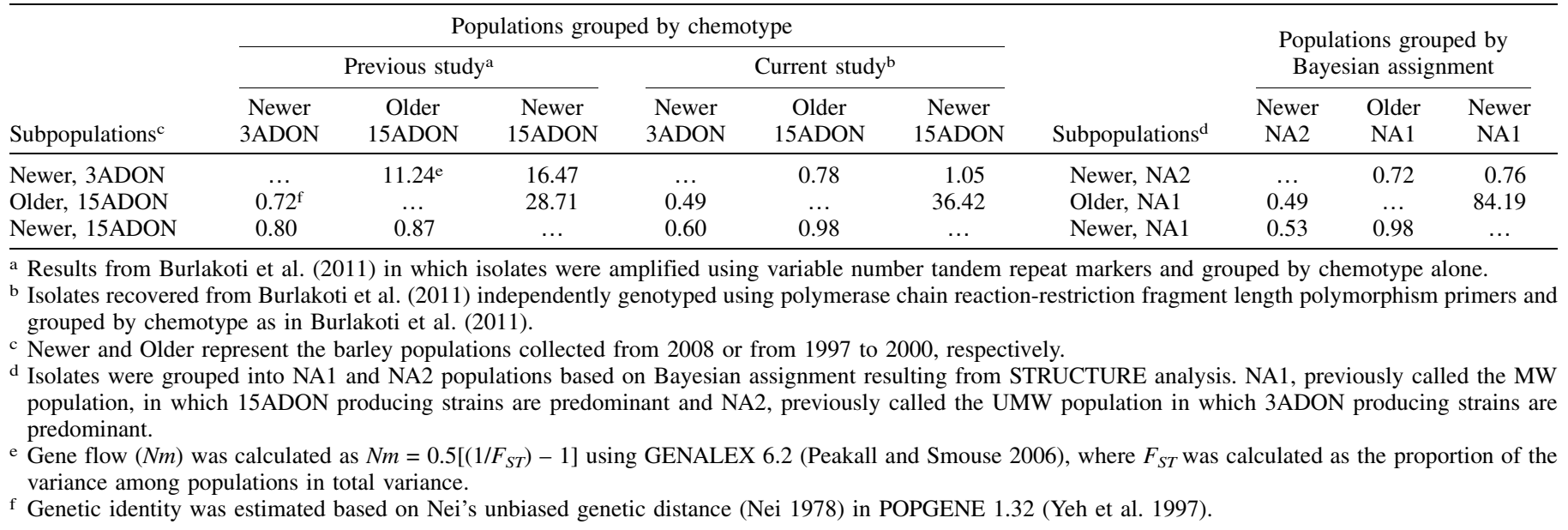


were grouped based on sampled region and year as in Burlakoti et al. (2011). Consistent with previous results, high genotypic diversity and low linkage disequilibrium were observed for strains from barley and wheat (Table 3). However, unlike the previous study, we found evidence for population subdivision within the most recently sampled isolates. While Burlakoti et al. (2011) found the frequency of $3 \mathrm{ADON}$ strains increased rapidly between their sampling time points, no evidence for population subdivision was inferred due to the high $N m$ and $I$ values between sampling periods. However, in the current study, lower linkage disequilibrium values were obtained for the older populations, which was consistent with Burlakoti et al. (2011) as well as Zeller et al. (2004), but $r D$ values in the newer barley and wheat collection suggested increased disequilibrium, apparently due to increased population structure arising from increasing frequency of NA2 population genotypes. Thus, our data indicated a pattern of population subdivision in the newer barley population.

In an effort to better understand the admixture potential and dynamics between these populations from wheat and barley, $41 \mathrm{pu}-$ tatively admixed isolates were intensively studied (Table 4). Higher admixture frequencies (Table 4) and lower pair-wise genetic variation between NA1 and NA2 (Table 6) in the wheat population compared with the barley population suggested more extensive gene flow within the wheat population. In addition, the ratio of admixture frequencies from wheat relative to barley increased from $1.73(10.9 \% / 6.3 \%)$ to $3.28(32.1 \% / 9.8 \%)$ (Table 4$)$ over the surveyed 8 to 10 years, which suggested faster dissemination of 3ADON genetic backgrounds and faster integration between NA1 and NA2 populations on wheat. Among wheat isolates, the frequency (16/30) of 15ADON isolates with NA2 genetic backgrounds $(\mathrm{Q}>0.5)$ was remarkably higher than the frequency $(1 / 30)$ of 3 ADON isolates with NA1 genetic backgrounds (Table 4). This is consistent with previous studies that found a bias favoring the genetic background of the NA2 population among admixed isolates from western Canadian wheat (Ward et al. 2008). A similar finding was also reported in an $F$. asiaticum population from barley, where the genetic background typical of a $3 \mathrm{ADON}$ population was found among admixed isolates with the NIV chemotype more frequently than the opposite combination (Zhang et al. 2010). Although a predominant directionality of introgression existed, both directions could be detected in the above two examples. Interestingly, $4.5 \%$ $(11 / 247)$ of $15 \mathrm{ADON}$ strains with NA2 genetic material was observed in the barley population of current study, but only one 3ADON strain (146 ND3) with NA1 genetic material was identified. Because NA2 strains, and the accompanying 3ADON chemotype, likely represent recent introductions into western Canada and the Upper Midwest (Burlakoti et al. 2011; Ward et al. 2008), we speculate that unidirectional gene flow in the barley population could be due to the selection for the NA2 genetic background, consistent with the increased frequency of the NA2 population as a whole. Moreover, slower dissemination of $3 \mathrm{ADON}$ strains on barley may reflect the additional time required for gene introgression in the barley population, leading to a strong signal of unidirectional gene flow. Overall, however, the exact mechanisms by which the NA1 and NA2 populations have remained largely distinct over the decade sampled in this study remain uncertain and worthy of further study.

As previously reported, the U.S. and Canadian populations of $F$. graminearum were essentially homogenous and almost exclusively of the 15ADON chemotype prior to the 1990s. However, population structure and diversity has increased dramatically over the last 10 to 20 years, as a novel genetic population (NA2) dominated by the 3ADON chemotype spread across Canada and the United States, bringing with it a variety of traits that may impart adaptive advantages over the previously dominant NA1 population (Burlakoti et al. 2011; Liang et al. 2014; Puri and Zhong 2010; Ward et al. 2008). Here, we document for the first time that this population heterogeneity extends to barley isolates from the Upper Midwest, contradicting a previous report suggesting that trichothecene chemotype polymorphism among barley isolates was not connected to population structure. Additional studies will be required to monitor the spread of the NA2 population as well as the 3ADON and $\mathrm{NX} 2$ chemotypes, and to evaluate potential differences in the relative competitive abilities of the different populations and chemotype on different hosts.

\section{ACKNOWLEDGMENTS}

We thank S. M. Neate, P. Gross, and R. Burlakoti (North Dakota State University) for providing published strains of $F$. graminearum from barley, and $\mathrm{K}$. Broz for technical assistance in laboratory work. This work was supported in part by the United States Wheat and Barley Scab Initiative. The mention of firm names or trade products does not imply that they are endorsed or recommended by the U.S. Department of Agriculture (USDA) over other firms or similar products not mentioned. The USDA is an equal opportunity provider and employer.

\section{LITERATURE CITED}

Abramson, D., Clear, R. M., Gaba, D., Smith, D. M., Patrick, S. K., and Saydak, D. 2001. Trichothecene and moniliformin production by Fusarium species from western Canadian wheat. J. Food Prot. 64:1220-1225.

Agapow, P. M., and Burt, A. 2001. Indices of multilocus linkage disequilibrium. Mol. Ecol. Notes 1:101-102.

Anonymous. 2015. National Agricultural Statistics Service (1993-1999) Annual Reports: Minnesota Agricultural Statistics, Minnesota Office, St. Paul and North Dakota Agricultural Statistics, North Dakota Office, Fargo. U.S. Department of Agriculture. http://www.nass.usda.gov/Statistics_by_State/

Bec, S., Ward, T., Farman, M., O’Donnell, K., Hershman, D., Van Sanford, D., and Vaillancourt, L. J. 2014. Characterization of Fusarium strains recovered from wheat with symptoms of head blight in Kentucky. Plant Dis. doi: 10.1094/PDIS-06-14-0610-RE

Burlakoti, R. R., Neate, S. M., Adhikari, T. B., Gyawali, S., Salas, B., Steffenson, B. J., and Schwarz, P. B. 2011. Trichothecene profiling and population genetic analysis of Gibberella zeae from barley in North Dakota and Minnesota. Phytopathology 101:687-695.

Evanno, G., Regnaut, S., and Goudet, J. 2005. Detecting the number of clusters of individuals using the software STRUCTURE. A simulation study. Mol. Ecol. 14:2611-2620

Foroud, N. A., McCormick, S. P., MacMillan, T., Badea, A., Kendra, D. F., Ellis, B. E., and Eudes, F. 2012. Greenhouse studies reveal increased aggressiveness of emergent Canadian Fusarium graminearum chemotypes in wheat. Plant Dis. 96:1271-1279.

Gale, L. R., Chen, L.-F., Hernick, C. A., Takamura, K., and Kistler, H. C. 2002. Population analysis of Fusarium graminearum from wheat fields in eastern China. Phytopathology 92:1315-1322.

Gale, L. R., Harrison, S. A., Ward, T. J., O’Donnell, K., Milus, E. A., Gale, S. W., and Kistler, H. C. 2011. Nivalenol-type populations of Fusarium graminearum and F. asiaticumare prevalent on wheat in southern Louisiana. Phytopathology 101:124-134.

Gale, L. R., Ward, T. J., Balmas, V., and Kistler, H. C. 2007. Population subdivision of Fusarium graminearum sensu stricto in the Upper Midwestern United States. Phytopathology 97:1434-1439.

Gilbert, J., Clear, R. M., Ward, T. J., Gaba, D., Tekauza, A., and Turkington, T. K. 2010. Relative aggressiveness and production of 3- or 15-acetyl deoxynivalenol and deoxynivalenol by Fusarium graminearum in spring wheat. Can. J. Plant Pathol. 32:146-152.

Guo, X. W., Fernando, W. G. D., and Seow-Brock, H. Y. 2008. Population structure, chemotype diversity, and potential chemotype shifting of Fusarium graminearum in wheat fields of Manitoba. Plant Dis. 92:756-762.

Jansen, C., Wettstein, D. V., Scha"fer, W., Kogel, K. H., Felk, A., and Frank, J. 2005. Infection patterns in barley and wheat spikes inoculated with wildtype and trichodiene synthase gene disrupted Fusarium graminearum. Proc. Natl. Acad. Sci. USA 102:16892-16897.

Láday, M., Juhász, Á., Mulè, G., Moretti, A., Szécsi, Á., and Logrieco, A. 2004. Mitochondria DNA diversity and lineage determination of European isolates of Fusarium graminearum (Gibberella zeae). Eur. J. Plant Pathol. 110:545-550.

Liang, J. M., Xayamongkhon, X., Broz, K., Dong, Y. H., McCormick, S. P., Abramova, S., Ward, T. J., and Kistler, H. C. 2014. Temporal dynamics and population genetic structure of Fusarium graminearum in the upper Midwestern United States. Fungal Genet. Biol. 73:83-92.

McMullen, M. P., Jones, R., and Gallenberg, D. 1997. Scab of wheat and barley: A re-emerging disease of devastating impact. Plant Dis. 81:13401348. 
Nei, M. 1973. Analysis of gene diversity in subdivided populations. Proc. Natl. Acad. Sci. USA 70:3321-3323.

Nei, M. 1978. Estimation of average heterozygosity and genetic distance from a small number of individuals. Genetics 89:583-590.

O'Donnell, K., Kistler, H. C., Tacke, B. K., and Casper, H. H. 2000. Gene genealogies reveal global phylogeographic structure and reproductive isolation among lineages of Fusarium graminearum, the fungus causing wheat scab. Proc. Natl. Acad. Sci. 97:7905-7910.

O’Donnell, K., Ward, T. J., Geiser, D. M., Kistler, H. C., and Aoki, T. 2004. Genealogical concordance between the mating type locus and seven other nuclear genes supports formal recognition of nine phylogenetically distinct species within the Fusarium graminearum clade. Fungal Genet. Biol. 41: 600-623.

Peakall, R., and Smouse, P. E. 2006. GENALEX 6: Genetic analysis in Excel. Population genetic software for teaching and research. Mol. Ecol. Notes 6: 288-295.

Pritchard, J. K., Stephens, M., and Donnelly, P. 2000. Inference of population structure using multilocus genotype data. Genetics 155:945-959.

Puri, K. D., and Zhong, S. 2010. The 3ADON population of Fusarium graminearum found in North Dakota is more aggressive and produces a higher level of DON than the prevalent $15 \mathrm{ADON}$ population in spring wheat. Phytopathology 100:1007-1014.

Qu, B., Li, H. P., Zhang, J. B., Xu, Y. B., Huang, T., Wu, A. B., Zhao, C. S., Carter, J., Nicholson, P., and Liao, Y. C. 2008. Geographic distribution and genetic diversity of Fusarium graminearum and F. asiaticum on wheat spikes throughout China. Plant Pathol. 57:15-24.

Ramirez, M. L., Reynoso, M. M., Farnochi, M. C., Torres, A. M., Leslie, J. F., and Chulze, S. N. 2007. Population genetic structure of Gibberella zeae isolated from wheat in Argentina. Food Addit. Contam. 24:1115-1120.

Schmale, D. G., Wood-Jones, A. K., Cowger, C., Bergstrom, G. C., and Arellano, C. 2011. Trichothecene genotypes of Gibberella zeae from winter wheat fields in the eastern USA. Plant Pathol. 60:909-917.

Seong, K. Y., Pasquali, M., Zhou, X., Song, J., Hilburn, K., McCormick, S., Dong, Y., Xu, J. R., and Kistler, H. C. 2009. Global gene regulation by Fusarium transcription factors Tri6 and Tri10 reveals adaptation for toxin biosynthesis. Mol. Microbiol. 72:354-367.

Spolti, P., Del, P. E. M., Cummings, J. A., Dong, Y., and Bergstrom, G. C. 2014. Fitness attributes of Fusarium graminearum isolates from wheat in New York possessing a 3ADON or 15ADON trichothecene genotype. Phytopathology 104:513-519.

Starkey, D. E., Ward, T. J., Aoki, T., Gale, L. R., Kistler, H. C., Geiser, D. M., Suga, H., Tóth, J., Varga, J., and O’Donnell, K. 2007. Global molecular surveillance reveals novel Fusarium head blight species and trichothecene toxin diversity. Fungal Genet. Biol. 44:1191-1204.
Steffenson, B. J. 2003. Fusarium head blight of barley: Impact, epidemics, management, and strategies for identifying and utilizing genetic resistance. Pages 241-295 in: Fusarium Head Blight of Wheat and Barley. K. J. Leonard and W. R., Bushnell, eds. The American Phytopathological Society, St. Paul, MN

Tóth, B., Mesterházy, Á., Horváth, Z., Bartók, T., Varga, M., and Varga, J. 2005. Genetic variability of central European isolates of the Fusarium graminearum species complex. Eur. J. Plant Pathol. 113:35-45.

Varga, E., Wiesenberger, G., Hametner, C., Ward, T. J., Dong, Y., Schöfbeck, D., McCormick, S., Broz, K., Stückler, R., Schuhmacher, R., Krska, R., Kistler, H. C., Berthiller, F., and Adam, G. 2015. New tricks of an old enemy: Isolates of Fusarium graminearum produce a novel type A trichothecene mycotoxin. Environ. Microbiol. 17:2588-2600.

Von der Ohe, C., Gauthier, V., Tamburic-Ilincic, L., Brule-Babel, A., Fernando, W. G. D., Clear, R., Ward, T. J., and Miedaner, T. 2010. A comparison of aggressiveness and deoxynivalenol production between Canadian Fusarium graminearum isolates with 3-acetyl and 15acetyldeoxynivalenol chemotypes in field grown spring wheat. Eur. J. Plant Pathol. 127:407-417.

Vujanovic, V., Goh, Y. K., and Daida, P. 2012. Heat- and cold-shock responses in Fusarium graminearum 3 acetyl- and 15 acetyl-deoxynivalenol chemotypes. J. Microbiol. 50:97-102.

Wang, J. H., Ndoye, M., Zhang, J. B., Li, H. P., and Liao, Y. C. 2011. Population structure and genetic diversity of the Fusarium graminearum species complex. Toxins (Basel) 3:1020-1037.

Ward, T. J., Bielawski, J. P., Kistler, H. C., Sullivan, E., and O'Donnell, K. 2002. Ancestral polymorphism and adaptive evolution in the trichothecene mycotoxin gene cluster of phytopathogenic Fusarium. Proc. Natl. Acad. Sci. USA 99:9278-9283.

Ward, T. J., Clear, R. M., Rooney, A. P., O’Donnell, K., Gaba, D., Patrick, S., Starkey, D. E., Gilbert, J., Geiser, D. M., and Nowicki, T. W. 2008. An adaptive evolutionary shift in Fusarium head blight pathogen populations is driving the rapid spread of more toxigenic Fusarium graminearum in North America. Fungal Genet. Biol. 45:473-484.

Yeh, F. C., Yang, R. C., Boyle, T. B. J., Ye, Z. H., and Mao, J. X. 1997. POPGENE, the User-Friendly Shareware for Population Genetic Analysis. Molecular Biology and Biotechnology Center, University of Alberta, Canada.

Zeller, K. A., Bowden, R. L., and Leslie, J. F. 2004. Population differentiation and recombination in wheat scab populations of Gibberella zeae from the United States. Mol. Ecol. 13:563-571.

Zhang, H., Zhang, Z., Van der Lee, T., Chen, W. Q., Xu, J., Xu, J. S., Yang, L., Yu, D., Waalwijk, C., and Feng, J. 2010. Population genetic analyses of Fusarium asiaticum populations from barley suggest a recent shift favoring 3ADON producers in southern China. Phytopathology 100:328-336. 